\title{
Estratégias de coping desenvolvidas por cuidadores de idosos portadores de doença crônica
}

\section{COPING STRATEGIES CAREGIVERS OF ELDERLY WITH CHRONIC DISEASES DEVELOP}

\author{
ESTRATEGIAS DE COPING DESARROLLADAS POR CUIDADORES DE ANCIANOS \\ PORTADORES DE ENFERMEDAD CRÓNICA
}

\author{
Janete Pessuto Simonetti ${ }^{1}$, Jóice Cristina Ferreira ${ }^{2}$
}

\begin{abstract}
RESUMO
Cuidar de um idoso com doença crônica pode representar uma ameaça e resultar em estresse. $O$ sucesso em lidar com esta situação dependerá do coping, definido como um processo utilizado para controlar as demandas da relação indivíduo-ambiente. Neste trabalho, o objetivo foi detectar as estratégias de coping utilizadas por cuidadores de idosos. Foi realizado um estudo qualitativo, com base na análise de discurso. A amostra foi composta por 16 indivíduos. As estratégias de coping mais utilizadas pelos cuidadores foram centradas na emoção e a tarefa de cuidar implica em mudanças em suas vidas, desempenhando as atividades sem auxílio, com sobrecarga, perda da liberdade e frustração. $O$ estresse maior está relacionado à falta de ajuda por parte dos familiares $e$ não à divisão das responsabilidades. Estimular o envolvimento da família, educar e fornecer orientações básicas, que possam minimizar as dificuldades do processo de cuidar, poderão contribuir para o bem-estar dos cuidadores.
\end{abstract}

\section{DESCRITORES}

Idoso.

Doença crônica.

Cuidadores.

Estresse.

Adaptação psicológica.

\begin{abstract}
Care for a dependent elderly individual with a chronic disease can be a threat and cause stress. Success in dealing with this situation will depend on coping strategies, defined as processes used in order to control the demands of the individualenvironment relationship. In this study the goal was to detect coping strategies used by caregivers for the elderly. A qualitative study was carried out through the analysis of coping discourse and theoretical reference. The sample was comprised of 16 individuals. It was observed that the coping strategies most used by caregivers were centered on emotion, and that caregiving tasks imply many changes in the life of caregivers, who perform them with no aid, with work overload, loss of liberty, and frustration. The greatest stress is related to the lack of help from family members and of shared responsibilities. Stimulating the involvement of the family, educating and giving basic orientation, which may reduce the difficulties of caregiving, could improve these individuals' well-being.
\end{abstract}

\section{KEY WORDS}

Aged.

Chronic disease.

Caregivers.

Stress.

Adaptation, psychological.

\section{RESUMEN}

Cuidar a un anciano con enfermedad crónica puede representar una amenaza y resultar en estrés. El éxito para lidiar con esta situación dependerá del coping, definido como un proceso utilizado para controlar las demandas de la relación individuo-ambiente. En este trabajo, el objetivo fue detectar las estrategias de coping utilizadas por cuidadores de ancianos. Fue realizado un estudio cualitativo, con base en el análisis de discurso. La muestra estuvo conformada por 16 individuos. las estrategias de coping más utilizadas por los cuidadores estuvieron centradas en la emoción y la tarea de cuidar implica en cambios en sus vidas, desempeñando las actividades sin ayuda, con sobrecarga, pérdida de la libertad y frustración. El mayor estrés está relacionado a la falta de ayuda por parte de los familiares y no a la división de las responsabilidades. Estimular el involucramiento de la familia, educar y proporcionar orientaciones básicas, que puedan minimizar las dificultades del proceso de cuidar, podrán contribuir en el bienestar de los cuidadores.

\section{DESCRIPTORES \\ Anciano. \\ Enfermedad crônica. \\ Cuidadores. \\ Estrés. \\ Adaptación psicológica.}

1 Enfermeira. Doutora. Professora Assistente do Departamento de Enfermagem da Faculdade de Medicina de Botucatu, Universidade Estadual Paulista (UNESP). Botucatu, SP, Brasil. jpessuto@fmb.unesp.br ${ }^{2}$ Enfermeira. Trabalho desenvolvido como Bolsista de Iniciação Científica da Fundação de Amparo à Pesquisa do Estado de São Paulo (FAPESP). São Paulo, SP, Brasil. jcfrodrigues@yahoo.com.br 


\section{INTRODUCÃ̃}

Cuidar de indivíduos idosos portadores de doenças crônicas pode gerar situações de estresse que, se não forem elaboradas adequadamente, poderão trazer transtornos tanto para o cuidador, como para o indivíduo doente e seus familiares.

No decorrer do processo de envelhecimento as doenças crônicas podem se manifestar, sendo mais freqüente hipertensão arterial, diabetes, doenças reumáticas, dentre outras ${ }^{(1)}$.

Após os 40 anos de idade há um declínio funcional fisiológico que se acentua ao longo da vida e que pode ser influenciado por diversos fatores como físicos, orgânicos, genéticos, hábitos de vida, meio-ambiente, condições educacionais e socioeconômicas, incluindo-se as relações familiares ${ }^{(1)}$.

De acordo com o grau de autonomia que os indivíduos idosos possuem, necessitam mais ou menos da atuação do cuidador. E a forma como se constrói essa relação de dependência parcial ou total poderá gerar situações de estresse.

O estresse é inevitável e faz parte da vida humana. Origina-se de demandas internas ou externas do indivíduo, sendo avaliado pelo mesmo de acordo com os recursos que disponibiliza para manter seu bem-estar ${ }^{(2)}$.

O estresse não está inteiramente no ambiente, nem no indivíduo, mas sim há um intercâmbio entre eles. As pessoas escolhem e moldam ativamente os eventos em suas vidas, mas as estratégias de coping não podem ser avaliadas sem referência das demandas ambientais que criam a necessidade delas. É essencial saber como cada situação se iniciou, moldou e restringiu tais estratégias ${ }^{(2)}$.

A reação ao estresse é desencadeada por um estímulo que é denominado estressor. A maneira pela qual o indivíduo interpreta esse estímulo, através de significados a ele atribuídos, experiências vividas, bem como pela função cognitiva é que vai transformar este estímulo em estressor ${ }^{(3)}$.

As estratégias de coping têm as funções de gerenciar ou alterar o estressor, sendo classificadas como centradas no problema e quando buscam controlar, reduzir ou eliminar as respostas emocionais diante do estressor são centradas na emoção(2).

As famílias que têm um de seus membros com problemas crônicos de saúde sentem, juntamente com ele, toda a problemática que envolve a questão. Ambos têm desafios ligados ao desempenho de novos papéis como trabaIhar com as perdas de atividades sociais, financeiras e de suas capacidades físicas ${ }^{(4)}$.
Os familiares tentam encontrar soluções para o cuidado de seus idosos, buscando assim evitar uma provável institucionalização. Porém, ao assumir tal compromisso, esta atitude nem sempre é a mais desejada pelos membros da família, mas muitas vezes é a única alternativa possível para atender às necessidades do indivíduo doente $e^{(5)}$.

Dentro do núcleo familiar o estresse pode ser dividido em objetivo e subjetivo. $O$ primeiro diz respeito às perturbações que afetam a vida em família na área financeira, no exercício de papéis, nas relações familiares da supervisão do idoso e nas relações com amigos e vizinhança. $O$ segundo está relacionado a sentimentos de sobrecarga, desamparo, perda de controle, falta de domínio, vergonha, exclusão, incômodo(4).

Na maioria das vezes, o cuidador familiar desempenha seu papel sozinho, sem ajuda de outros familiares ou de profissionais. Neste caso ele se configura como cuidador principal e representa o elo entre o idoso, a família e a equipe de saúde(6).

Podemos observar que uma doença crônica pode trazer transtornos, tanto para o portador como para o responsável pelo cuidado desse indivíduo. Isto porque, desempenhar este papel pode gerar mudanças e sobrecarga, bem como estresse, interferindo na vida do cuidador.

Para as pessoas idosas a família é o refúgio no qual elas encontram proteção, solidariedade e afetividade. Porém, quando as doenças ocorrem há uma quebra no equilíbrio familiar ${ }^{(7)}$.

Indivíduos que convivem com pessoas que necessitam de constantes cuidados de saúde podem demonstrar os mais diversos sentimentos que permeiam este processo, desde cansaço, estresse, exaustão, mas também, bem-estar, afeição e ternura. $O$ cansaço como resultado do processo de cuidar é uma condição humana que requer reflexão e ajuda para o familiar cuidador ${ }^{(8)}$.

Os órgãos públicos deveriam ter um interesse maior frente ao crescimento da população idosa, no que se refere às políticas sociais, levando em consideração as características demográficas, econômicas, sociais e de saúde do país(9).

Quanto ao auxílio familiar ao idoso, há diversas dificuldades como falta de políticas sociais de suporte aos cuidadores, diminuição do tamanho das famílias com a queda da fecundidade, aumento das separações conjugais, famílias com idosos que possuem renda familiar de no máximo três salários mínimos, suporte formal incapaz de substituir a família ${ }^{(10)}$.

A maioria dos cuidadores relata ter sentimentos de impotência e incompetência para desempenhar algumas 
tarefas específicas que envolvem o cuidar de indivíduos deficientes físicos. Eles vêem o familiar como um estranho em seu ambiente que cada dia revela um novo ser, com novas necessidades ${ }^{(11)}$.

Ao se analisar o discurso destes cuidadores, suas narrativas apontam para as dificuldades da realidade diária, como conviver com o sofrimento e a dor, permeado por sentimentos ambíguos que se originam nos conflitos $\operatorname{afetivos}^{(11)}$.

Ao assumir o cuidado de um indivíduo com deficiência esta tarefa é realizada com sofrimento e privações, tendo como base a culpa e a religiosidade e como suporte a afetividade ambígua ${ }^{(11)}$.

Diversos estudos discutem sobre o papel do cuidador sendo avaliado por familiares que desempenham esta atividade como gerador de estresse e ônus. Alguns dos estressores mencionados por cuidadores de idosos são: cuidados diretos e contínuos e necessidade de constante vigilância; falta de preparo e conhecimento para executar o cuidado; problemas de saúde associados ao excesso de trabalhado e à idade avançada; conflitos familiares pela falta de divisão do trabalho e de reconhecimento por parte de outros membros da família; dificuldades de adaptação à nova situação, incluindo aspectos financeiros, redução de atividades profissionais, sociais e de $\operatorname{lazer}^{(12)}$.

Adaptar-se ou não a um dado acontecimento, enfrentar situações semelhantes de formas bastante diversificadas, depende de inúmeros fatores que englobam aspectos culturais, emocionais, vivências anteriores e características pessoais.

Cuidar de um indivíduo idoso, dependente, portador de uma doença crônica, pode representar uma ameaça constante, já que esta situação é geradora de estresse.

Neste estudo tivemos como objetivo detectar as estratégias de coping apresentadas por indivíduos cuidadores de pessoas idosas portadoras de doenças crônicas.

\section{MÉTODO}

Foi feito um estudo qualitativo usando-se a Análise de Discurso do Sujeito Coletivo (DSC) para o agrupamento das informações coletadas. Esta forma de análise permite ao pesquisador captar o que é expresso pelo sujeito, possibilitando acesso a dados da realidade de caráter subjetivo, como crenças, idéias, opiniões, sentimentos, comportamentos $^{(13)}$.

Esta pesquisa foi desenvolvida junto a indivíduos que executam o papel de cuidadores de pessoas idosas portadoras de doenças crônicas que eram atendidas em um Centro de Saúde Escola de uma cidade do interior do Estado de São Paulo, pertencente à Universidade Estadual Paulista.
Para a constituição da amostra foram estabelecidos os seguintes critérios: ser cuidador de um indivíduo idoso portador de doença crônica e concordar em participar da pesquisa. Não se considerou o grau de dependência dos idosos, mas sim a necessidade de um cuidador.

As entrevistas foram feitas nos domicílios, sem a presença do idoso para o qual se prestava o cuidado. A amostra foi composta por 16 pessoas que desempenhavam o papel de cuidador, caracterizada como intencional e o seu tamanho foi definido pela saturação das respostas, como é preconizado para pesquisas qualitativas.

Os dados foram obtidos no período de fevereiro a maio de 2001 , através de questões abertas lidas pela pesquisadora e as respectivas respostas foram gravadas em fitas magnéticas, sendo feita transcrição literal dos conteúdos.

O instrumento de coleta de dados foi composto pela idade, sexo, grau de instrução, estado marital, ocupação e questões abertas que abrangeram aspectos quanto às pessoas que poderiam prestar o cuidado, doença do idoso, opinião do cuidador em relação à prestação do cuidado e em relação às estratégias de coping utilizadas.

Esta pesquisa foi apreciada e aprovada pelo Comitê de Ética em Pesquisa da Faculdade de Medicina de Botucatu, Unesp (Processo n. 198/00) e os indivíduos que concordaram em participar da mesma assinaram o Termo de Consentimento Livre e Esclarecido.

O DSC é uma estratégia metodológica que auxilia na visualização de uma representação social e o conjunto das representações que conforma um dado imaginário. Torna possível visualizar a representação social, não sob forma de tabelas, quadros ou categorias, mas sim como os indivíduos reais pensam ${ }^{(13)}$.

A organização dos dados foi baseada na utilização de figuras metodológicas que auxiliaram na organização dos depoimentos. As figuras são: idéia central, expressõeschave e discurso do sujeito coletivo ${ }^{(13)}$.

A idéia central é a afirmação que permite traduzir a essência do discurso emitido pelo indivíduo. As expressões-chave são transcrições literais de parte dos depoimentos que fornecem a essência do conteúdo discursivo. O discurso do sujeito coletivo é constituído a partir de categorias que representam os depoimentos e que os tornam equivalentes por expressarem a mesma idéia, representados simbolicamente pela categoria(13).

Para a análise e discussão dos dados foi utilizado o referencial teórico de coping para a apresentação das estratégias detectadas junto aos cuidadores.

\section{RESULTADOS E DISCUSSÃO}

Características dos participantes: dos 16 indivíduos, 12 tinham idade acima de 50 anos e 15 eram do sexo feminino. 
Tais resultados podem ser usados para se refletir sobre os encargos familiares que a mulher desempenha na sociedade. Apesar da emancipação feminina e da sua crescente presença no mercado de trabalho, as atividades domésticas ainda são assumidas pelas mulheres, trabaIhando ou não fora de casa.

Quando um familiar adoece, dificilmente um homem assume seus cuidados diretos. Ele pode contribuir secundariamente, (transporte, promoção de atividades sociais, questões legais, dentre outros), mas os cuidados primários são prestados por mulheres, na maioria dos casos, pelo próprio papel que ela desempenha no contexto familiar.

Em relação ao grau de instrução, estado civil e ocupação, 11 participantes cursaram o ensino fundamental, oitos eram casados e oito se ocupavam de afazeres domésticos.

Quanto ao grau de parentesco, todos os entrevistados (16 pessoas) eram parentes dos idosos para os quais desempenhavam o papel de cuidadores, sendo que nove eram filhos, três esposas, duas sobrinhas, uma neta e uma nora. Tal fato permite se observar que há uma estreita ligação entre o cuidador e o idoso e o quanto essa tarefa é desempenhada por um membro da família.

Quanto ao conhecimento do cuidador sobre a doença do idoso, apesar da variedade de doenças citadas, a Hipertensão Arterial foi mencionada por nove indivíduos, seguida de Diabetes (quatro citações) e de Acidente Vascular Encefálico (três citações).

Embora os entrevistados soubessem dizer o nome da doença estes não compreendiam o significado da mesma e suas implicações.

Uma das dificuldades dos cuidadores é de entender a doença e suas complicações, muitas vezes ficando na dúvida se está prestando o cuidado de forma correta. 0 despreparo do cuidador pode trazer sérios riscos à saúde do indivíduo que necessita deste cuidado, simplesmente pela falta de orientação adequada ${ }^{(14)}$.

Quanto à possibilidade de a prestação de cuidados ser realizada por outras pessoas, dos 16 entrevistados, 11 responderam que outros familiares poderiam auxiliar na prestação de cuidados, mas que tal fato não ocorria. Um participante respondeu que dividia sua tarefa com outro membro da família e quatro disseram que não tinham com quem dividir tais tarefas.

Desempenhar a tarefa de cuidar de um indivíduo idoso com doença crônica por si já é uma atividade desgastante. Quando esta é assumida apenas por um familiar, tal atividade se torna ainda mais estressante, causando frustrações e perdas sociais.
Cuidar de um indivíduo doente pode levar a diversos fatores estressantes que vão desde dificuldade financeira a fatores de ordem emocional. Muitas vezes as pessoas que exercem tal atividade têm vontade de abandonar tudo, mas não o fazem, principalmente, por uma questão de caridade e por se sentirem obrigadas a realizar estas funções, mesmo que isto represente grandes prejuízos na sua vida pessoal ${ }^{(15)}$.

\section{Estratégias de coping dos cuidadores}

Para a organização dos dados obtidos nas entrevistas optou-se pela estratégia metodológica do DSC que permite se ter uma visão mais clara de uma dada representação social, bem como do conjunto de representações que constituem um dado imaginário(13).

A tabulação de dados que se originam de questões abertas ocorre através da identificação de uma palavra, um conceito ou uma expressão que revele a essência da resposta, denominada de categoria. Daí a composição do DSC se originar de trechos dos discursos individuais de cada membro participante do estudo, agrupados na mesma categoria pela sua semelhança e equivalência na expressão das idéias ${ }^{(13)}$.

Para a análise dos DSC e o levantamento das estratégias de coping apresentadas pelos cuidadores dos idosos utilizou-se do referencial teórico de coping.

Duas questões foram feitas aos participantes, no sentido de se detectar as estratégias de coping utilizadas frente ao ato de cuidar de idosos portadores de doenças crônicas.

Questão $n^{\circ}$ 1: Como tem sido cuidar de um idoso doente?

\section{Idéia Central:}

\section{Cuidar não é uma tarefa fácil, exige atenção constante e cuidados redobrados.}

\section{Discurso do Sujeito Coletivo}

Cuidar é difícil porque tem que ficar o tempo todo atrás, verificando se comeu, se tomou os remédios, principalmente devido à dependência física, à dificuldade de se locomover e realizar higiene. Perdem-se os momentos de lazer e se vive muito em função do outro o que acaba gerando tensão e estresse. Esta tarefa de cuidar se torna mais difícil quando o cuidador também apresenta problemas de saúde e se torna uma tarefa mais fácil quando o grau de dependência é menor.

A dificuldade do cuidar não está somente na realização das tarefas em si, mas também na dedicação necessária para satisfazer as necessidades do outro, em detrimento das suas próprias necessidades. 
Neste DSC se observa que os cuidadores sentiam a perda da liberdade e que suas vidas se limitavam muito a cuidar do outro, não desfrutando de atividades de lazer, o que causava infelicidade e desânimo.

Os cuidadores, quando relatam suas dificuldades, não se limitam a atividades específicas do cuidado, pois há muita subjetividade nas respostas que se relacionam à dinâmica familiar e aos seus sentimentos ${ }^{(14)}$.

Esta subjetividade está presente nas mudanças de papéis familiares, no medo, no constrangimento de prestar o cuidado, pelo fato da invasão de privacidade e intimidade do indivíduo que pode ser o pai, a mãe, o sogro. Com o passar do tempo, tais dificuldades se tornam insignificantes, pois podem ser substituídas por outras, como falta de recursos financeiros e materiais ${ }^{(14)}$.

Questão $n^{\circ}$ 2: Como você tem enfrentado essa situação?

\section{Idéia Central:}

\section{Cuidar é um dever, exige paciência e o apoio vem da religião.}

\section{Discurso do Sujeito Coletivo}

\begin{abstract}
Cuido porque é um dever e não se pode abandonar uma pessoa que está precisando de ajuda, mudou muito a minha rotina. Há tantas coisas que não posso mais fazer como sair de casa, ir ao mercado, pois estou sempre preocupada com o que possa acontecer se eu me ausentar. Tenho enfrentado como dá, sempre com muita paciência, pois minha vida ficou muito limitada. Até gostaria de receber ajuda, mas acabo não recebendo. Busco ajuda na religião, pois se Deus me deu essa cruz para carregar, eu vou levá-la até o fim e de um jeito ou de outro, tenho que enfrentar.
\end{abstract}

No segundo DSC pode-se notar a busca de ajuda na religião para enfrentar esta situação, além do prejuízo da vida social do cuidador.

O modo de enfrentar uma situação de estresse é em parte determinada pela sua história passada, seus valores, suas crenças pessoais, pela sua avaliação da situação e pelos recursos pessoais e sociais disponíveis para lidar com o evento estressante ${ }^{(16)}$.

As estratégias de coping são classificadas como: centradas no problema, quando se faz uso do processo de solução de problema, como enumerar alternativas e escolher uma ação e centradas na emoção quando há uma tentativa de aliviar ou regular o impacto emocional do estresse no indivíduo, mesmo que as condições da situação não tenham mudado(2).

Observa-se que, conforme apresentação dos DSC, os indivíduos usaram estratégias de coping baseadas na emoção. Tais estratégias não atuam sobre o problema, na tentativa de resolvê-lo, mas sim amenizam situações que, supostamente, não podem ser modificadas.
Talvez a utilização de estratégias centradas na emoção se dê pelo fato de ser a única saída encontrada por esses indivíduos para lidarem com esta situação de estresse, visto que não há a possibilidade de se contratar outras pessoas para ajudarem no cuidado devido à questão financeira. Falar com os outros familiares seria uma estratégia centrada no problema, mas talvez por um certo comodismo, pelo fato de outros familiares morarem longe e não demonstrarem interesse em participar desta tarefa ou por tentativas frustradas de divisão dos cuidados isto não seja mais visto como possível.

Diversos estudos apontam para uma crescente necessidade do cuidado domiciliar, sendo que o cuidado informal vem e continuará sendo realizado pelos próprios membros da família, principalmente devido a condições crônicas de saúde ${ }^{(14)}$.

Para que a Política Nacional de Saúde do Idoso possa ser praticada na sua essência, uma das necessidades é a capacitação de recursos humanos especializados e o desenvolvimento de programas para os cuidados informais $^{(17)}$.

De acordo com os problemas que são observados na realização do cuidado, os cuidadores necessitam de programas de apoio que poderiam ser atendimento domiciliar, serviço de cuidador substituto, serviços de orientação e encaminhamento para profissionais da área da saúde ${ }^{(18)}$.

Estes profissionais precisam rever as questões que envolvem a assistência domiciliar, visto que, com o crescimento da população idosa, a tendência será aumentar o número de portadores de doenças crônicas. Oferecer tais serviços poderá amenizar o estresse da família que necessita deste auxílio.

A capacitação de indivíduos que cuidam de idosos é um recurso valioso que pode oferecer orientações gerais sobre o cuidado propriamente dito, bem como oferecer um espaço para que o cuidador possa expor suas ansiedades e dificuldades ${ }^{(17)}$.

Muitas vezes, o que se observa é que, inicialmente, a família se vê sensibilizada e até assustada com o que está acontecendo com um familiar e oferece todo e qualquer apoio tanto ao doente quanto à pessoa que se dispõe a cuidar do mesmo.

Entretanto, com o passar do tempo, adaptação e aceitação do fato vai se instalando e aquele que assumiu tal responsabilidade se vê, na maioria das vezes, sozinho, sem qualquer tipo de ajuda, renunciando a sua própria vida, enquanto os outros estão cuidando apenas de si próprios.

Isto ficou evidente nesta pesquisa. Em nenhum momento foram citados pelos cuidadores aspectos da prática assistencial, para os quais se pretendia contribuir. A ênfase foi sempre dada na falta de apoio e no abandono de suas atividades, enquanto ser social. 
Observa-se que as estratégias de coping mais utilizadas pelos cuidadores entrevistados foram centradas na emoção, pois não envolviam um processo de resolução do problema, apenas tentavam amenizar a situação, seja através da religião ou da renúncia. Também se constatou que a tarefa de cuidar implica em muitas mudanças na vida do cuidador que, na maioria dos casos, desempenha esta atividade sozinho. Os cuidadores sentem-se sobrecarregados, perdendo sua liberdade, gerando frustrações.

Essa busca centrada na emoção pode ser vista como a única saída para enfrentar as dificuldades que encontram na realização do cuidar de um indivíduo idoso, dependente, portador de uma doença crônica.

Estes cuidadores relatam em seus discursos que a falta de ajuda, por parte da família, é o ponto central para este tipo de estratégia de coping. Pois, eles têm claro que se houvesse divisão de trabalho, poderiam dedicar mais tempo para si próprios, sem terem que renunciar as suas próprias vontades.

Talvez já tenham tentado mudar esta situação, porém como não obtiveram sucesso, passaram a enfrentar tal problema, sem a busca da solução, mas tentando resolvêlo da melhor forma possível, através da renúncia, da religião, do desânimo, mas sempre tentando atender às necessidades do indivíduo doente.

Há ainda um fator cultural que pode estar influenciando tais estratégias de coping, sendo o cuidar visto como uma obrigação. Tanto que muitas famílias não procuram por uma instituição ou pela ajuda de um profissional. Como se não cuidar diretamente implicasse em abandono.

Observa-se que o estresse maior desses cuidadores está relacionado à falta de ajuda, no sentido de divisão de responsabilidades com outros membros da família, e não com o cuidar propriamente dito.

Talvez, uma forma de ajudar estes indivíduos seria, nos atendimentos, procurar envolver a família mais ati-

\section{REFERÊNCIAS}

1. Brasil. Ministério da Saúde. Instituto para o Desenvolvimento da Saúde. Universidade de São Paulo. Programa Saúde da Família. Manual de enfermagem. São Paulo; 2001.

2. Lazarus RS, Folkman S. The concept of coping. In: Monart A, Lazarus RS. Stress and coping: an anthology. $3^{\text {th }}$ ed. New York: Columbia University Press; 1991.

3. Lipp MEN. O stress está dentro de você. São Paulo: Contexto; 2000.

4. Neri AL. Qualidade de vida e idade madura. Campinas: Papirus; 1993. Bem estar e estresse em familiares que cuidam de idosos fragilizados e de alta dependência; p. 237-82. vamente neste processo, atuando na educação e fornecendo orientações básicas, com uma perspectiva encorajadora que possa, de alguma maneira, minimizar suas dificuldades e auxiliar a família a planejar e providenciar os recursos necessários para um esquema de cuidados ao paciente crônico. Esclarecer a família quanto aos seus direitos, estimulando-a a fazer uso dele, como também dos recursos existentes na comunidade.

\section{CONSIDERAÇÕES FINAIS}

A interação com o meio ambiente é constante, estímulos são recebidos, respostas são emitidas, que podem demonstrar afetividade, sinais do estado de espírito e quais interpretações estão sendo feitas diante dos fatos da vida.

Trabalhar com situações que geram estresse pode ser um grande desafio, visto que cada indivíduo reage de diferentes maneiras diante de um estressor comum.

Com o desenvolvimento deste trabalho observou-se quanto pode ser estressante cuidar de um indivíduo doente. As dificuldades na divisão das tarefas com outros familiares, a falta de condição financeira para contratar alguém tecnicamente preparado.

Há muito que se desenvolver na área da saúde para se melhorar a assistência que pode ser oferecida a uma família que está enfrentando a situação de cuidar de um indivíduo idoso, portador de uma doença crônica.

Além de se preparar, adequadamente, profissionais capazes para prestar esta assistência, precisa-se também elaborar um programa para os cuidadores, para que o ato de cuidar não seja somente sinônimo de renúncia, de ausência de vida social, de falta de liberdade para cuidar de si próprio. O ponto de inserção destes indivíduos poderia ser a própria unidade de saúde de sua área, através de um programa político-social, colocando em prática o que já existe no papel quanto à política nacional do idoso.

5. Queiroz ZPV. Cuidando do idoso: uma abordagem social. Mundo Saúde. 2000;24(4):246-48.

6. Kawasaki K, Diogo MJD’E. Assistência domiciliária ao idoso: perfil do cuidador formal. Parte 1. Rev Esc Enferm USP. 2001;35(2):257-64.

7. Paula $A A D$, Furegato $A R$, Scatena MCM. Interação enfermeiro-familiar de paciente com comunicação prejudicada. Rev Lat Am Enferm. 2000;8(4):45-51.

8. Marques S, Rodrigues RAP, Kusumota L. Cerebrovascular accident in the aged: changes in family relations. Rev Lat Am Enferm. 2006;14(3):364-71. 
9. Davim RMB, Torres GV, Dantas SMM, Lima VM. Estudo com idosos de instituições asilares no município de Natal/RN: características socioeconômicas e de saúde. Rev Lat Am Enferm. 2004;12(3):518-24.

10. Chaimowicz F. Os idosos brasileiros do século XXI: demografia, saúde e sociedade. Belo Horizonte: Postgraduate; 1998.

11. Azevedo GR, Santos VLCG. (Handicapped) caregiver: the social representations of family members about the caregiving process. Rev Lat Am Enferm. 2006;14(5):77080.

12. Gonçalves LHT, Alvarez AM, Santos SMA. Os cuidadores leigos de pessoas idosas. In: Duarte YAO, Diogo MJD'E, organizadores. Atendimento domiciliar: um enfoque gerontológico. São Paulo: Atheneu; 2000. p. 102-10.

13. Lefèvre $F$, Lefèvre $A M C$, Teixeira JJV. O discurso do sujeito coletivo: uma nova abordagem metodológica em pesquisa qualitativa. Caxias do Sul: EDUCS; 2000.
14. Perlini NMOG, Faro ANM. Cuidar de pessoa incapacitada por acidente vascular cerebral no domicílio: o fazer do cuidador familiar. Rev EsC Enferm USP. 2005;39(2):154-63.

15. Bocchi SCM. Movendo-se entre a liberdade e a reclusão: vivendo uma experiência de poucos prazeres ao vir-a-ser um familiar cuidador de uma pessoa com AVC [tese]. São Paulo: Escola de Enfermagem, Universidade de São Paulo; 2001.

16. Gimenes MGG, Queiroz E, Shayer BPM. Reações emocionais diante do câncer: sugestões para intervenção. Arq Bras Med. 1992;66(4):353-56.

17. Diogo MJD, Ceolim MF, Cintra FA. Orientações para idosas que cuidam de idosos no domicílio. Rev Esc Enferm USP. 2005;39(1):97-102.

18. Brasil. Ministério da Justiça. Secretaria Nacional dos Direitos Humanos. Programa Nacional de Direitos Humanos. Política Nacional do Idoso. Brasília; 1998. 